\title{
OLIVEIRA, C.M.R. Metafísica e ética. A filosofia da pessoa em Lima Vaz como resposta ao niilismo contemporâneo. Coleção Estudos Vazianos. São Paulo: Loyola, 2013, 295p.
}

Elton Vitoriano Ribeiro ${ }^{1}$

O livro Metafísica e ética de Cláudia Oliveira, professora de metafísica da FAJE, é fruto de seu doutorado em filosofia na Pontifícia Universidade Gregoriana (Roma, Itália). Segundo a própria autora, este livro quer explicitar num grande panorama o percurso de Lima Vaz, na intenção de ser "uma introdução à sua proposta de reler a metafísica de Tomás de Aquino à luz da dialética platônico-hegeliana" (OLIVEIRA,2013,p.22). Este panorama, desenhado pela autora tem dois núcleos de atração, a metafísica e a ética na modernidade. Modernidade que Lima Vaz esforçou-se por compreender seus projetos, caminhos, descaminhos, conquistas e desilusões (OLIVEIRA,2013,p.25). Neste esforço, Lima Vaz fez em sua obra uma grande rememoração percorrendo toda a história da filosofia para pensar filosoficamente a existência humana num mundo. Mundo contemporâneo em contínua, rápida e variada transformação.

A pergunta inicial que guia a autora, em sua reflexão é muito interessante. Lima Vaz, em seu pensamento, distanciando-se da filosofia pós-metafísica, no livro "Introdução à ética filosófica 2" afirma: não há ética sem metafísica. A partir daí a autora se pergunta: existe uma relação necessária entre metafísica e ética? Nos termos da autora: "Se, por um lado, para Lima Vaz não há ética sem metafísica, por outro lado, é possível

${ }^{1}$ Professor de Filosofia - FAJE: Faculdade Jesuíta <eltonvitoriano@gmail.com> 
afirmar que para ele exista metafísica sem ética?" (OLIVEIRA,2013,p.12). Aqui está, em germe, desenhado todo o percurso do livro que vai se desdobrando e encontrando dificuldades a ser analisadas. A primeira é a seguinte: o que Lima Vaz entende por metafísica? A pergunta pela ética, outro núcleo importante da reflexão foi respondida por Lima Vaz em vários livros e artigos, especialmente nos dois volumes de "Introdução á ética filosófica". Mas, por outro lado, Lima Vaz nunca escreveu um livro de metafísica. Daí podemos perceber o valor da investigação da autora em resgatar a questão metafísica presente no pensamento de Lima Vaz. Ou, filosoficamente, resgatar a compreensão de Lima Vaz desta experiência de abertura ilimitada ao horizonte transcendente, fundamento e origem de toda experiência que o ser humano faz do próprio ser e do próprio agir.

Segundo a autora, Lima Vaz entende a metafísica num duplo sentido: um estrito e outro amplo (OLIVEIRA,2013,p.13). Em sentido estrito, a metafísica é o discurso que explicita diretamente a experiência do Uno. Em sentido amplo, é todo percurso que parte do múltiplo e se dirige ao Uno. Ora, Lima Vaz inspirado em Tomás de Aquino "estabelece a relação necessária entre a ética entendida como ontologia do agir humano e a metafísica entendida tanto em sentido estrito como em sentido amplo" (OLIVEIRA,2013,p.14). É esta relação que a autora busca elucidar. A elucidação tem como pano de fundo duas questões fundamentais sempre presentes no pensamento de Lima Vaz: (1) o problema do sentido da existência e (2) a pergunta a respeito da orientação ética para as ações humanas.

Este percurso elucidativo da autora, acerca do pensamento de Lima Vaz, tem como horizonte de realização a modernidade e a pósmodernidade. Na modernidade o desafio ao pensamento metafísico se configura na primazia da racionalidade técnico-científica e da exacerbação da subjetividade. Na pós-modernidade, o desafio é o avanço do niilismo ético e metafísico que questiona constantemente todas as tentativas de reflexão e ação. Assim, diante disso, a proposta de Lima Vaz é fazer memória do ser a partir de uma releitura dialética da metafísica de Tomás de Aquino. Didaticamente, a autora divide sua investigação em duas partes com três capítulos cada.

A primeira parte tem por título "Um percurso filosófico: ponto de partida, método e opção teórica". Nela a autora identifica algumas questões importantes que acompanham a reflexão filosófica de Lima Vaz. 
Pensar a existência e o agir humanos a partir da situação história é uma delas. A outra é pensar esta problemática a partir da abertura ilimitada ao horizonte transhistórico da Verdade e do Bem. Por isso, o primeiro desafio da autora é pensar a "Modernidade e o Niilismo" (capítulo 1). Neste capítulo, a reflexão caminha na direção de elucidar a interpretação da modernidade de Lima Vaz. Surge um enigma, o enigma da modernidade que tem que enfrentar a racionalidade moderna e a autonomia da razão técnico-científica, que se apresentam como desafios para o nosso tempo. Diante destes desafios o método filosófico de Lima Vaz é o "Método dialético" (capítulo 2). Segundo a autora, para Lima Vaz a dialética é um caminho de reflexão que parte de aporias concretas. Como método, Lima Vaz é devedor da filosofia de Platão e Hegel. Cada um destes filósofos, analisados pela autora em suas reflexões acerca da dialética filosófica em seus contextos, influencia Lima Vaz. Assim, Lima Vaz constrói seu próprio método buscando também, refletindo sobre os dualismos presentes na história, a unidade de sentido tão importante para a filosofia. Finalmente, no terceiro capítulo, a autora busca explicitar a reconstrução que Lima Vaz faz da metafísica tomista. "A opção por Tomás de Aquino" (capítulo 3) faz este trabalho importante de reler os textos sobre Tomás de Aquino; textos escritos por Lima Vaz e publicados ao longo de sua carreira filosófica. Reler e interpretá-los ajudando o leitor a compreender a importância fundamental da metafísica de Tomás de Aquino no pensamento de Lima Vaz.

Na segunda parte do livro o foco é a "Filosofia realista da pessoa" de Lima Vaz. Segundo a autora, a filosofia da pessoa de Lima Vaz é uma via alternativa ao niilismo pós-moderno, analisado na primeira parte, o qual Lima Vaz se apresenta como um crítico feroz. Esta filosofia da pessoa vaziana se apresenta como uma proposta de releitura dialética da metafísica de Tomás de Aquino inspirada na estrutura triádica da filosofia do espírito de Hegel (OLIVEIRA,2013,p.17). Ora, sendo aristotélicotomista, esta filosofia tem um tríplice nivelamento: a pessoa humana, a pessoa moral e a pessoa absoluta. "A Pessoa Humana" (capítulo 4) deve ser interpretada filosoficamente a partir da experiência que cada um de nós faz do próprio ser. Nossa experiência, para Lima Vaz, acontece numa síntese dinâmica entre essência e existência. Nesta síntese, a pergunta fundamental que guia a busca de sentido à vida humana é: quem sou eu? Pergunta inalienável e fundamental para o ser humano e que guia também 
toda reflexão filosófica. Na busca de uma resposta o ser humano se descobre como ser em ato porque "aquilo que ele é por essência deve tornar-se na existência concreta" (OLIVEIRA,2013,p.18). Assim, neste percurso de indagação o ser humano se descobre como um ser paradoxal, um ser histórico. Mas, também, como não poderia ser diferente para a filosofia de Lima Vaz, um ser aberto ao horizonte transcendental da verdade. Os outros dois capítulos são, evidentemente, desdobramentos deste primeiro. "A Pessoa Moral" (capítulo 5) reflete sobre a pessoa a partir da famosa pergunta aristotélica, apropriada por Lima Vaz em sua filosofia: como convém viver? Pergunta ética por excelência ela quer apontar para a busca de significação da pessoa humana como pessoa moral. Pessoa moral que aponta, segundo Lima Vaz, contra muitas correntes filosóficas contemporâneas, para "A Pessoal Absoluta" (capítulo 6). Este sexto capítulo é o mais exigente na leitura, e para bem apreciá-lo em toda a sua potência é exigido profundos conhecimentos de metafísica, especialmente, metafísica tomista. Neste capítulo, no qual a autora demonstra seus profundos e articulados conhecimentos de metafísica, o caminho é lento e, por vezes, penoso. Diga-se de passagem, como deve ser todo caminho profundamente filosófico. A autora faz dialogar com Lima Vaz, para ajudar o leitor na compressão desta "experiência metafísica do ser absoluto que se constitui como condição de possibilidade da experiência do nosso ser como unidade dinâmica de essência e existência" (OLIVEIRA,2013,p.18), autores como J. B. Lotz (Transzendentale Erfahrung), J. Marechal (Le point de départ de la métaphysique) e J. De Finance (Existence et liberte), entre outros. Neste capítulo, Tomás de Aquino, Hegel e Heidegger são referências constantes na elucidação da experiência metafísica do Absoluto seja pela "via compositionis ou descensos", seja pela "via resolutionis ou ascensus". Neste percurso a autora conclui que "ao seguir o personalismo cristão, Lima Vaz também defende que o Absoluto real, afirmando em sua pessoalidade, constitui-se como fundamento último da pessoa humana. A experiência metafísica remete, pois, à experiência religiosa da Pessoa Humana" (OLIVEIRA,2013,p.270). Concluindo, para a autora "a experiência ontológica que fazemos do nosso próprio ser e agir nos remete à experiência metafísica como experiência do fundamento" (OLIVEIRA,2013,p.270).

A conclusão final da autora é de que "toda a filosofia de Lima Vaz deve, pois, ser interpretada a partir do seguinte pressuposto fundamental: 
ele era um cristão e sua filosofia é uma filosofia cristã. Ela nasce da experiência profunda da abertura radical ao transcendente e pretende ser tematização discursiva dessa experiência radical como resposta ao enigma de um tempo histórico" (OLIVEIRA,2013,p.273). No caso o nosso tempo histórico, onde somos convidados a responder a pergunta fundamental pelo sentido. Pergunta que nos coloca diante da realidade história, diante das aporias do pensamento, diante de nossa própria existência com os outros no mundo. Neste percurso, que parte da experiência ôntica, rumo às experiências ontológica, metafísica e religiosa; somos também nós, convencidos pela filosofia de Lima Vaz que existe uma "íntima ligação não apenas entre ética e metafísica, mas também entre metafísica e ética" (OLIVEIRA,2013,p.279). Portanto, temos aqui uma excelente reflexão filosófica que merece ser lida por todos os que se ocupam com o labor filosófico de alta qualidade em nosso país. 